ARTICLE

Received 30 Apr 2014 | Accepted 14 Jul 2014 | Published 22 Aug $2014 \quad$ DOl: 10.1038/ncomms5695

\title{
Nanoscale nickel oxide/nickel heterostructures for active hydrogen evolution electrocatalysis
}

Ming Gong ${ }^{1, \star}$, Wu Zhou ${ }^{2, \star}$, Mon-Che Tsai ${ }^{3}$, Jigang Zhou ${ }^{4}$, Mingyun Guan${ }^{1}$, Meng-Chang Lin ${ }^{1}$, Bo Zhang ${ }^{1}$, Yongfeng $\mathrm{Hu}^{4}$, Di-Yan Wang ${ }^{1}$, Jiang Yang${ }^{1}$, Stephen J. Pennycook ${ }^{5}$, Bing-Joe Hwang ${ }^{3} \&$ Hongjie Dai ${ }^{1}$

Active, stable and cost-effective electrocatalysts are a key to water splitting for hydrogen production through electrolysis or photoelectrochemistry. Here we report nanoscale nickel oxide/nickel heterostructures formed on carbon nanotube sidewalls as highly effective electrocatalysts for hydrogen evolution reaction with activity similar to platinum. Partially reduced nickel interfaced with nickel oxide results from thermal decomposition of nickel hydroxide precursors bonded to carbon nanotube sidewalls. The metal ion-carbon nanotube interactions impede complete reduction and Ostwald ripening of nickel species into the less hydrogen evolution reaction active pure nickel phase. A water electrolyzer that achieves $\sim 20 \mathrm{~mA} \mathrm{~cm}^{-2}$ at a voltage of $1.5 \mathrm{~V}$, and which may be operated by a single-cell alkaline battery, is fabricated using cheap, non-precious metal-based electrocatalysts.

\footnotetext{
${ }^{1}$ Department of Chemistry, Stanford University, Stanford, California 94305, USA. ${ }^{2}$ Materials Science and Technology Division, Oak Ridge National Laboratory, Oak Ridge, Tennessee 37831, USA. ${ }^{3}$ Department of Chemical Engineering, National Taiwan University of Science and Technology, Taipei 10607 , Taiwan, ROC. ${ }^{4}$ Canadian Light Source Inc., Saskatoon, Saskatchewan, Canada SK S7N 0X4. ${ }^{5}$ Department of Materials Science and Engineering, The University of Tennessee, Knoxville, Tennessee 37996, USA. * These authors contributed equally to this work. Correspondence and requests for materials should be addressed to H.D. (email: hdai@stanford.edu).
} 
$\mathrm{H}$ ydrogen, as a clean and renewable energy resource, has been intensely investigated as an alternative to the diminishing fossil fuel ${ }^{1-4}$. An effective way of producing high-purity hydrogen is to electrochemically split water into hydrogen and oxygen in an electrolyzer ${ }^{5-10}$. Nickel $(\mathrm{Ni})$ and stainless steel are typically used in industry for water reduction and oxidation catalysis respectively in basic solutions ${ }^{7,11}$. However, Ni metal is not an ideal water reduction or hydrogen evolution reaction (HER) catalyst due to its high overpotential $(\sim 200 \mathrm{mV})$ and large Tafel slope ${ }^{11,12}$. The state-of-art HER catalyst is platinum $(\mathrm{Pt})$ and its alloys, but the scarcity and cost of Pt limit its large-scale application for electrolysis ${ }^{13}$. Active and stable non-precious metal-based HER catalysts in alkaline solutions have been pursued ${ }^{14-23}$ including Raney $\mathrm{Ni}^{16,17}$ and Nickel molybdenum (NiMo) alloy 14,15,18,19,21. It remains difficult to achieve both high activity and stability matching those of Pt.

Here, we report a nickel oxide/nickel (NiO/Ni) heterojunction-like structure attached to mildly oxidized carbon nanotube $(\mathrm{NiO} / \mathrm{Ni}-\mathrm{CNT})$ exhibiting high HER catalytic activity close to commercial $\mathrm{Pt} / \mathrm{C}$ catalysts in several types of basic solutions ( $\mathrm{pH}=9.5-14)$. The $\mathrm{NiO} / \mathrm{Ni}$ nano-hybrids is fabricated serendipitously in a low-pressure thermal annealing experiment, affording partial reduction of nickel hydroxide $\left(\mathrm{Ni}(\mathrm{OH})_{2}\right)$ coated on oxidized CNTs that acts as an interacting substrate to impede complete reduction and aggregation of $\mathrm{Ni}$. The high catalytic activity of $\mathrm{NiO} / \mathrm{Ni}-\mathrm{CNT}$ towards HER enables a high-performance electrolyzer with $\sim 20 \mathrm{~mA} \mathrm{~cm}^{-2}$ at a voltage of $1.5 \mathrm{~V}$.

\section{Results}

Synthesis and characterization of $\mathrm{NiO} / \mathrm{Ni}-\mathrm{CNT}$ catalyst. $\mathrm{NiO} /$ $\mathrm{Ni}$-CNT synthesis was done by low-temperature hydrolysis of $\mathrm{Ni}$ salts into Ni hydroxide on the sidewalls of mildly oxidized CNT $\left[\mathrm{Ni}(\mathrm{OH})_{2} / \mathrm{ox}-\mathrm{CNT}\right]$, followed by a low-pressure ( $\sim 1.5$ torr) annealing at $300^{\circ} \mathrm{C}$ in an Ar flow. The synthesis was very simple and could be easily scaled up for practical use. Scanning transmission electron microscopy (STEM) images revealed the presence of $\sim 10 \mathrm{~nm}$ nanoparticles attached to multi-walled CNT (Fig. 1a,b). Chemical mapping with electron energy-loss spectroscopy (EELS) resolved the distribution of $\mathrm{O}, \mathrm{Ni}$ and $\mathrm{C}$ with sub-nm spatial resolution, identifying a core shell-like structure with $\mathrm{O}$ and $\mathrm{Ni}$ in the shell and only $\mathrm{Ni}$ in the core (Fig. 1d-f) over a CNT network. High-resolution STEM imaging (Fig. 1b and Supplementary Fig. 1) and the corresponding chemical mapping (Fig. 1d) showed that the $\mathrm{NiO}$ shell was not uniform, containing small $\mathrm{NiO}$ grains with different orientations and might contain small gaps in the shell to expose some $\mathrm{NiO} / \mathrm{Ni}$ nano-interfaces (Fig. 1c).

X-ray photoelectron spectroscopy (XPS) confirmed the NiO-Ni structure (Supplementary Fig. 2a). The as-made material exhibited mostly $\mathrm{Ni}^{2}+$ species on the surface with a weak
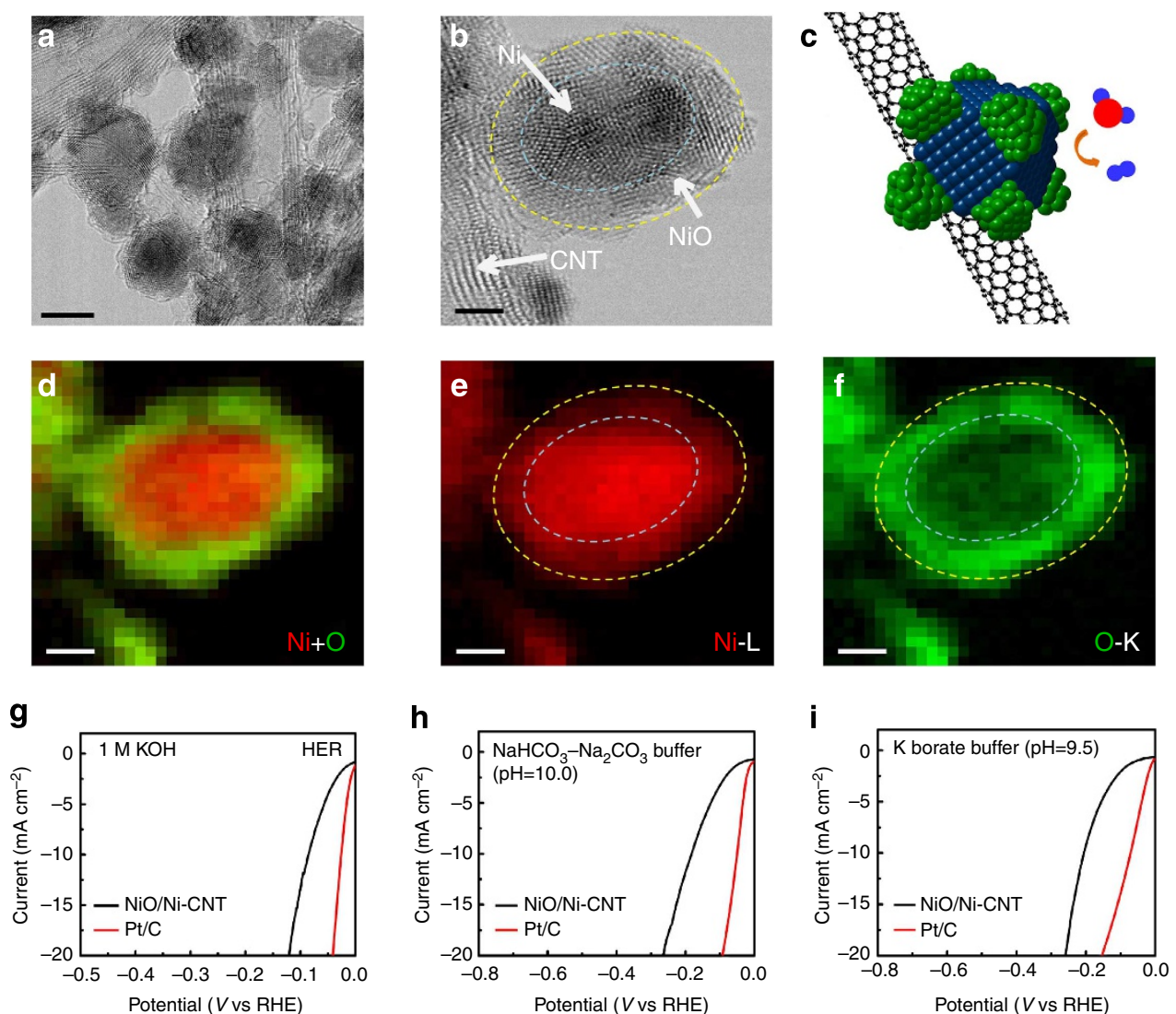

Figure 1 | Structure and performance of a highly active NiO/Ni-CNT nano-hybrid. (a) Low-magnification STEM bright-field image showing the typical morphology of the NiO/Ni-CNT sample, with $8-15 \mathrm{~nm}$ particles attached to CNTs. Scale bar, $2 \mathrm{~nm}$. (b) Atomic resolution STEM bright-field image showing the structure of a typical $\mathrm{NiO} / \mathrm{Ni}$ particle on a CNT (small NiO nanoparticles over a larger Ni nanoparticle core). Scale bar, $2 \mathrm{~nm}$. (c) A schematic illustration of the NiO/Ni-CNT structure. Scale bar, $2 \mathrm{~nm}$. (d-f) Chemical maps for the spatial distribution of $\mathrm{Ni}$ and $\mathrm{O}$ and their overlay, from the whole area shown in $\mathbf{b}$. The two dashed circles highlight the $\mathrm{NiO}$ particle layer on the surface of the Ni core. Scale bar, $2 \mathrm{~nm}$. (g-i) Linear sweep voltametry of $\mathrm{NiO} / \mathrm{Ni}-\mathrm{CNT}$ and $\mathrm{Pt} / \mathrm{C}$ in $\mathbf{g} 1 \mathrm{M} \mathrm{KOH}(\mathbf{h}) \mathrm{NaHCO}_{3}-\mathrm{Na}_{2} \mathrm{CO}_{3}$ buffer $(\mathrm{pH}=10.0)$ and (i) potasium borate buffer $(\mathrm{pH}=9.5)$ at a scan rate of $1 \mathrm{mVs}{ }^{-1}$ under the loading of $0.28 \mathrm{mg} \mathrm{cm}^{-2}$ on RDE showing high HER catalytic activity of $\mathrm{NiO} / \mathrm{Ni}-\mathrm{CNT}$. 
shoulder peak at $\sim 853 \mathrm{eV}$ from $\mathrm{Ni}^{0}$. On Ar ion sputtering of the surface, the detected $\mathrm{Ni}$ species were mostly $\mathrm{Ni}^{0}$ with decreased amount of $\mathrm{Ni}^{2+}$, consistent with $\mathrm{NiO}$-decorated $\mathrm{Ni}$ nanoparticles. The $\mathrm{Ni} \mathrm{K}$ edge spectrum of the sample recorded by X-ray absorption near edge spectroscopy (XANES) further corroborated the co-existence of $\mathrm{NiO}$ and $\mathrm{Ni}$ (Supplementary Fig. 2b). Since $\mathrm{Ni}$ K edge probed deeper into the material, we could estimate the $\mathrm{Ni} / \mathrm{NiO}$ ratio $\sim 73 / 27$ by linear fitting of standard patterns.

The HER catalytic property of $\mathrm{NiO} / \mathrm{Ni}-\mathrm{CNT}$ was measured in a three-electrode configuration by with a rotating disk electrode (RDE) at 1,600 r.p.m. to remove $\mathrm{H}_{2}$ bubbles generated. Commercial $\mathrm{Pt} / \mathrm{C}$ was investigated side-by-side under the same loading of $0.28 \mathrm{mg} \mathrm{cm}^{-2}$. In $1 \mathrm{M}$ potassium hydroxide (KOH), the $\mathrm{NiO} / \mathrm{Ni}$-CNT afforded little overpotential at low current density with only a slightly lower current increase compared to $\mathrm{Pt} / \mathrm{C}$ and a Tafel slope of $82 \mathrm{mV}$ per decade (Fig. $1 \mathrm{~g}$ and Supplementary Fig. 3a). Impressively, the $\mathrm{NiO} / \mathrm{Ni}$-CNT catalyst achieved an HER current density of $10 \mathrm{~mA} \mathrm{~cm}^{-2}$ at $<100 \mathrm{mV}$ overpotential. Moreover, high-performance HER catalysis by $\mathrm{NiO} / \mathrm{Ni}-\mathrm{CNT}$ was also observed in a carbonate/bicarbonate buffer $(\mathrm{pH}=10.0)$ and a borate buffer $(\mathrm{pH}=9.5$; Fig. $1 \mathrm{~h}, \mathrm{i})$.

Synergistic effects of $\mathrm{NiO}$ and $\mathrm{Ni}$ on HER catalysis. When annealed at $300^{\circ} \mathrm{C}$ at a higher Ar pressure of $1 \mathrm{~atm}$ (in contrast to $\sim 1.5$ torr for producing $\mathrm{NiO} / \mathrm{Ni}-\mathrm{CNT}$ ), the same $\mathrm{Ni}(\mathrm{OH})_{2}$ precursors on CNTs was transformed to pure $3-4 \mathrm{~nm} \mathrm{NiO}$ nanoparticles (NiO/CNT; Fig. $2 \mathrm{~b}$ and Supplementary Fig. 4), suggesting no $\mathrm{Ni}^{2}+$ reduction under a high annealing pressure with the release of oxygen gas. On the other hand, $\mathrm{Ni}^{2+}$ reduction was accelerated by raising the annealing temperature to $500^{\circ} \mathrm{C}$ in $\sim 1.5$ torr $\mathrm{Ar}$, generating $\mathrm{Ni}$ nanoparticles (mostly $>10 \mathrm{~nm}$ particles) nearly free of $\mathrm{NiO}$ on $\mathrm{CNTs}(\mathrm{Ni} / \mathrm{CNT}$; Fig. $2 \mathrm{c}$ and Supplementary Fig. 4). The Ni surface oxidation state on $\mathrm{NiO} / \mathrm{CNT}$ and $\mathrm{Ni} / \mathrm{CNT}$ were confirmed to be +2 and 0 , respectively, by XPS and XANES spectra (Fig. 2g,h) and by EELS chemical mapping (Fig. 2e,f and Supplementary Figs 5 and 6).

The NiO/CNT material afforded a much larger overpotential of $\sim 400 \mathrm{mV}$, despite a smaller Tafel slope and CNT alone showed negligible HER current density before $-0.5 \mathrm{~V}$ versus RHE (Supplementary Fig. 7). The Ni/CNT hybrid gave similar Tafel slope in HER but a larger overpotential of $\sim 130 \mathrm{mV}$ than the $\sim 0 \mathrm{mV}$ overpotential for $\mathrm{NiO} / \mathrm{Ni}-\mathrm{CNT}$. This advantage was partially attributed to the higher surface area of $\mathrm{NiO} / \mathrm{Ni}-\mathrm{CNT}$ $\left(152.2 \mathrm{~m}^{2} \mathrm{~g}^{-1}\right)$ compared with that of Ni/CNT $\left(86.5 \mathrm{~m}^{2} \mathrm{~g}^{-1}\right.$; Supplementary Fig. 8a). With current density normalized to the surface area instead of the geometric area, $\mathrm{NiO} / \mathrm{Ni}-\mathrm{CNT}$ still outperformed Ni/CNT by $\sim 100 \mathrm{mV}$ (Supplementary Fig. 8b). Further, we compared the HER activity of a physical mixture of $\mathrm{Ni} / \mathrm{CNT}$ and $\mathrm{NiO} / \mathrm{CNT}$ with $\mathrm{Ni} / \mathrm{CNT}$ alone, without observing any difference and both were inferior to $\mathrm{NiO} / \mathrm{Ni}-\mathrm{CNT}$ (Supplementary Fig. 9). These results suggested that the HER catalytic activity might be facilitated by a synergistic effect between $\mathrm{NiO}$ and $\mathrm{Ni}$.

Important role of $\mathrm{CNT}$ in $\mathrm{NiO} / \mathrm{Ni}$ heterostructure synthesis. It is interesting that the formation of $\mathrm{NiO} / \mathrm{Ni}$ heterostructure relied on the oxidized CNT growth substrate. Without any CNT as support, the same reaction steps produced aggregated $\mathrm{Ni}$ particles a

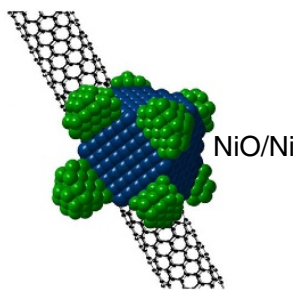

d

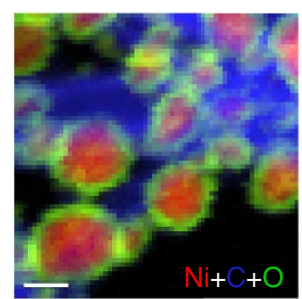

g

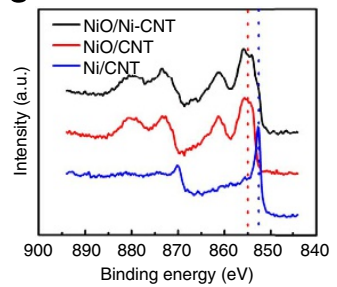

b

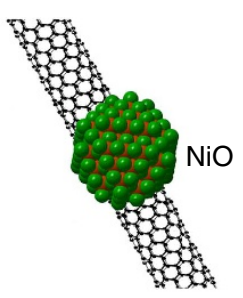

e

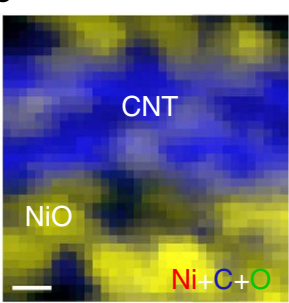

h

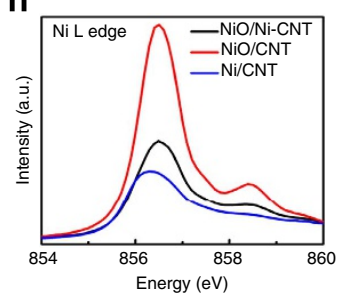

c

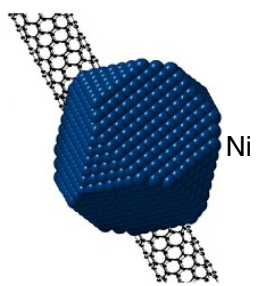

f

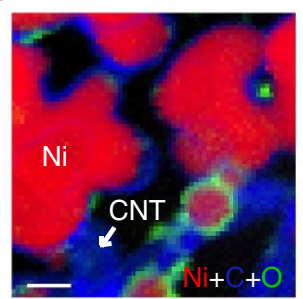

i

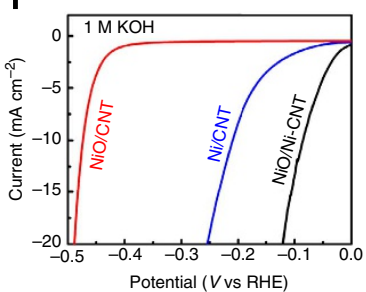

Figure 2 | Structure and performance of NiO/Ni-CNT compared with NiO/CNT and Ni/CNT. (a-c) Schematic illustrations of (a) NiO/Ni-CNT, (b) $\mathrm{NiO} / \mathrm{CNT}$ and (c) Ni/CNT structure. (d-f) Reconstructed elemental maps with $\mathrm{Ni}$ in red, $\mathrm{C}$ in blue and $\mathrm{O}$ in green for (d) $\mathrm{NiO} / \mathrm{Ni}$-CNT, scale bar is $5 \mathrm{~nm}$ (e) $\mathrm{NiO} / \mathrm{CNT}$, scale bar is $2 \mathrm{~nm}$ and (f) Ni/CNT structure, scale bar is $10 \mathrm{~nm}$. (g) High-resolution Ni XPS spectra of the three hybrid materials (the dotted line points out the binding energy of $\mathrm{Ni}^{2+}$ (red) and metallic Ni (blue). (h) Ni L edge XANES spectra of the three hybrid materials. (i) Linear sweep voltametry of the three hybrid materials in $1 \mathrm{M} \mathrm{KOH}$ at a scan rate of $1 \mathrm{mVs}^{-1}$ under the loading of $0.28 \mathrm{mg} \mathrm{cm}^{-2}$ on RDE showing superior HER catalytic activity of $\mathrm{NiO} / \mathrm{Ni}-\mathrm{CNT}$. 
in a plate-like morphology (Fig. 3a) with lower HER activity than $\mathrm{NiO} / \mathrm{Ni}-\mathrm{CNT}$ (Fig. $3 \mathrm{~b}$ and Supplementary Fig. 10), in strong contrast to the small nanoparticle structure of $\mathrm{NiO} / \mathrm{Ni}$ on $\mathrm{CNT}$ (Fig. 3a). NiO/Ni heterostructures growing on oxidized CNT with different oxidation degree showed similar HER catalytic activity in $1 \mathrm{M} \mathrm{KOH}$ (Supplementary Fig. 11). These results suggested that on oxidized CNTs, the reduction of oxidized $\mathrm{Ni}$ species during thermal decomposition was impeded or retarded likely due to pinning or interactions of Ni species with oxidized CNTs through oxygen functional groups, delaying the reduction of $\mathrm{Ni}$ into larger aggregates via Ostwald ripening. This result was observed serendipitously and underscored that substrateprecursor interaction could profoundly affect the morphology, structure and catalytic activity of materials.

Water electrolysis by $\mathrm{NiO} / \mathrm{Ni}-\mathrm{CNT}$ and NiFe LDH. Towards electrolysis applications, we loaded the $\mathrm{NiO} / \mathrm{Ni}-\mathrm{CNT}$ material into $\mathrm{Ni}$ foam at a high loading of $\sim 8 \mathrm{mg} \mathrm{cm}^{-2}$ (based on mass of $\mathrm{NiO} / \mathrm{Ni}$ ). The HER catalytic activity of the electrode was high in $1 \mathrm{M} \mathrm{KOH}$, showing $<100 \mathrm{mV}$ overpotential at a current density of $100 \mathrm{~mA} \mathrm{~cm}^{-2}$ and an impressively low Tafel slope of $51 \mathrm{mV}$ per decade (Fig. 4a and Supplementary Fig. 3, please refer to Supplementary Fig. 12 for uncompensated curve, Supplementary Fig. 13 for mean value and s.d. of applied potential at certain current densities and Supplementary Table 1 for comparison with other representative HER electrocatalysts). There was only a slight difference in the activity between $\mathrm{NiO} / \mathrm{Ni}-\mathrm{CNT}$ and precious metal Pt/C catalyst ( $\sim 20 \mathrm{mV} @ 20 \mathrm{~mA} \mathrm{~cm}^{-2}$ and $\sim 50 \mathrm{mV}$ @ $100 \mathrm{~mA} \mathrm{~cm}^{-2}$ ). Compared with bare $\mathrm{Ni}$ foam that resembled

a
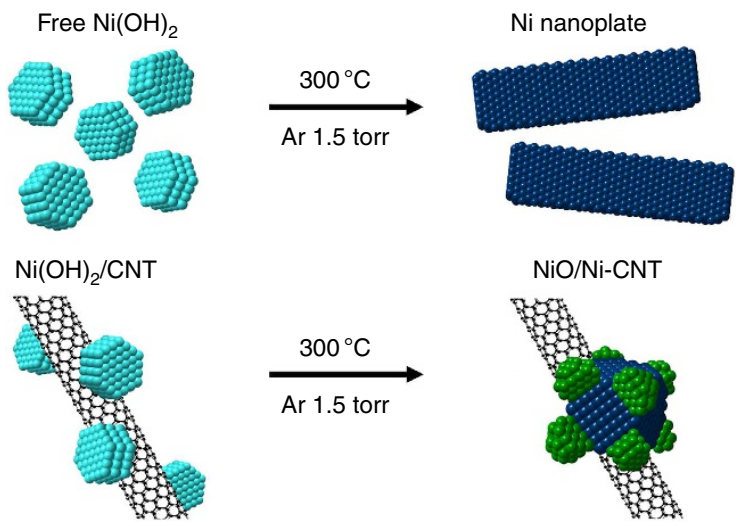

b

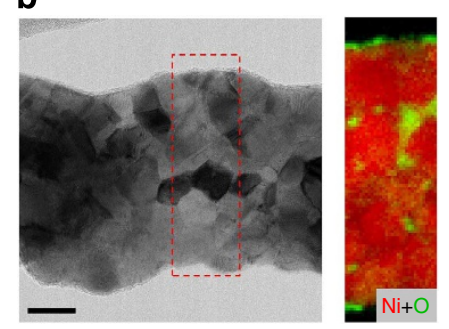

C
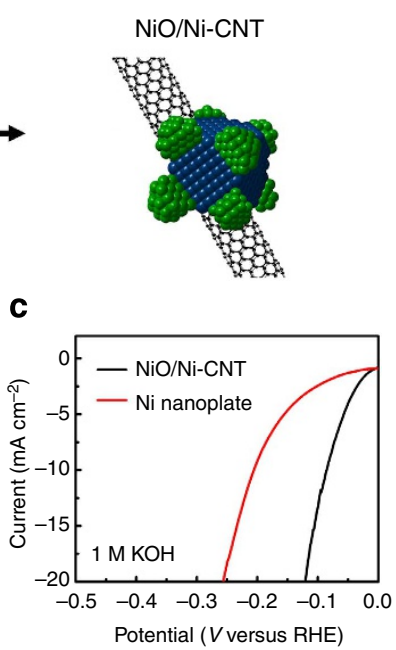

Figure 3 | Different products made by the same reaction with and without oxidized CNT. (a) A schematic illustration of the structural difference between CNT hybrid and pure nanoparticle (b) STEM BF image showing the typical morphology of the CNT-free Ni nanoplate and the corresponding reconstructed maps from the highlighted area with $\mathrm{Ni}$ in red and $\mathrm{O}$ in green. Only a very small amount of $\mathrm{NiO}$ particles is observed on the surface. Scale bar, $20 \mathrm{~nm}$. (c) Linear sweep voltametry of NiO/Ni-CNT hybrid and CNT-free $\mathrm{Ni}$ nanoplate in $1 \mathrm{M} \mathrm{KOH}$ at a scan rate of $1 \mathrm{mVs}^{-1}$ under the loading of $0.28 \mathrm{mg} \mathrm{cm}^{-2}$ on RDE.
$\mathrm{Ni}$ foil used in industrial water splitting, the $\mathrm{NiO} / \mathrm{Ni}-\mathrm{CNT}$ electrode afforded a gain of $\sim 200 \mathrm{mV}$ lower in voltage (Fig. 4a). Similar gain of $\sim 300 \mathrm{mV}$ over $\mathrm{Ni}$ foam was obtained in bicarbonate-carbonate buffer and borate buffer electrolytes, respectively (Supplementary Fig. 14a,b). In addition, the constant current curves of $\mathrm{NiO} / \mathrm{Ni}-\mathrm{CNT}$ at HER region exhibited good stability to maintain a high HER current density of $20 \mathrm{~mA} \mathrm{~cm}^{-2}$ over the course of $2 \mathrm{~h}$ in all three electrolytes (Supplementary Fig. 14c).

We made an electrolyzer using $\mathrm{NiO} / \mathrm{Ni}-\mathrm{CNT}$ as water reduction catalyst and a high-performance $\mathrm{NiFe}$-layered double hydroxide $(\mathrm{NiFe} \mathrm{LDH})$ water oxidation catalyst ${ }^{28}$. The experiment was carried out in $1 \mathrm{M} \mathrm{KOH}$ at room temperature $\left(\sim 23^{\circ} \mathrm{C}\right)$ and $\sim 60^{\circ} \mathrm{C}$. Water electrolysis with low current density of $20 \mathrm{mAcm}-2$ at $\sim 1.50 \mathrm{~V}$ and high current density of $100 \mathrm{mAcm}-2$ at $\sim 1.58 \mathrm{~V}$ was observed at room temperature (Fig. 4b). Notably, this was the first time ever reported to achieve a voltage of $<1.5 \mathrm{~V}$ for water electrolysis using non-precious catalysts for both electrodes. Such water electrolysis could be powered by a single-cell AAA battery with a nominal voltage of $\sim 1.5 \mathrm{~V}$ (Fig. $4 \mathrm{~d}$ and see Supplementary Movie 1 for a movie of water electrolysis by an AAA battery). The kinetics and thermodynamics were greatly improved at high temperature $\left(\sim 60^{\circ} \mathrm{C}\right.$ ), showing lower voltage of $\sim 1.42 \mathrm{~V}$ at $20 \mathrm{~mA} \mathrm{~cm}^{-2}$ and higher current increase, reaching $100 \mathrm{~mA} \mathrm{~cm}^{-2}$ at a voltage of $\sim 1.45 \mathrm{~V}$ (Fig. 4b) with good stability (Fig. 4c and Supplementary Fig. 15). The result suggested that the $\mathrm{NiO} / \mathrm{Ni}$ heterostructure catalyst could match the benchmark Pt/C catalyst for efficient electrolyzers with ultralow overpotential for water-splitting devices.

\section{Discussion}

Due to the observation of gaps in the $\mathrm{NiO}$ shell and thus incomplete coverage of the $\mathrm{Ni}$ core by $\mathrm{NiO}$, we proposed that the exposed $\mathrm{NiO} / \mathrm{Ni}$ nano-interfaces might be synergistically active sites for HER catalysis. In alkaline media, the HER pathway could be through the Volmer-Heyrovsky process or Volmer-Tafel pathways $^{24,25}$.

$$
\begin{aligned}
& \mathrm{H}_{2} \mathrm{O}+\mathrm{e} \rightarrow \mathrm{H}_{\mathrm{ads}}+\mathrm{OH}^{-}(\text {Volmer }) \text { and } \\
& \mathrm{H}_{\mathrm{ads}}+\mathrm{H}_{\mathrm{ads}} \rightarrow \mathrm{H}_{2}(\text { Tafel }) \\
& \mathrm{H}_{2} \mathrm{O}+\mathrm{e} \rightarrow \mathrm{H}_{\mathrm{ads}}+\mathrm{OH}^{-}(\text {Volmer }) \text { and } \\
& \mathrm{H}_{2} \mathrm{O}+\mathrm{H}_{\mathrm{ads}}+\mathrm{e} \rightarrow \mathrm{H}_{2}+\mathrm{OH}^{-} \text {(Heyrovsky) }
\end{aligned}
$$

Both pathways involve the adsorption of $\mathrm{H}_{2} \mathrm{O}$ molecule, electrochemical reduction of adsorbed $\mathrm{H}_{2} \mathrm{O}$ into adsorbed $\mathrm{OH}^{-}$and $\mathrm{H}$ atom, desorption of $\mathrm{OH}^{-}$to refresh the surface and formation of $\mathrm{H}$ adsorbed intermediate for $\mathrm{H}_{2}$ generation. $\mathrm{Ni}$ metal has been calculated to have a suitable $\mathrm{H}$ atom binding energy close to Pt (refs 26,27), but is much worse in HER catalytic activity compared with $\mathrm{Pt}$. Therefore, we tentatively propose that the formation and desorption of $\mathrm{OH}^{-}$might be an important step for HER in alkaline condition. On a $\mathrm{NiO} / \mathrm{Ni}$ interface, the $\mathrm{OH}^{-}$generated by $\mathrm{H}_{2} \mathrm{O}$ splitting could preferentially attach to a $\mathrm{NiO}$ site at the interface due to strong electrostatic affinity to the locally positively charged $\mathrm{Ni}^{2}+$ species and more unfilled $\mathrm{d}$ orbitals in $\mathrm{Ni}^{2}+$ than $\mathrm{Ni}$ metal, while a nearby $\mathrm{Ni}$ site would facilitate $\mathrm{H}$ adsorption and thus the Volmer process, imparting synergistic HER catalytic activity to $\mathrm{NiO} / \mathrm{Ni}$. A pure $\mathrm{NiO}$ surface is not active for HER due to the lack of $\mathrm{H}$ adsorption sites. On a pure $\mathrm{Ni}$ surface without any $\mathrm{NiO}$, the adsorbed $\mathrm{OH}^{-}$species could occupy the sites for $\mathrm{H}$ atom, causing inefficient release of $\mathrm{OH}^{-}$and blocking of the active catalytic sites.

Admittedly, detailed mechanistic insights into electrocatalysis of the heterostructure $\mathrm{NiO} / \mathrm{Ni}$ material are currently limited 
a

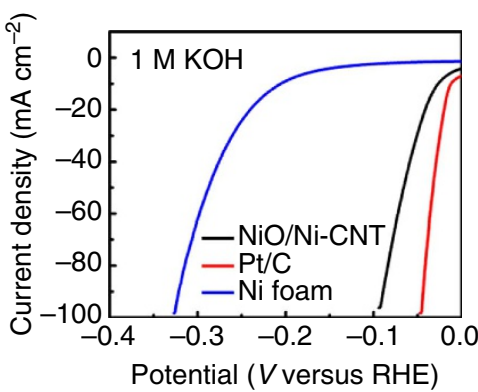

C

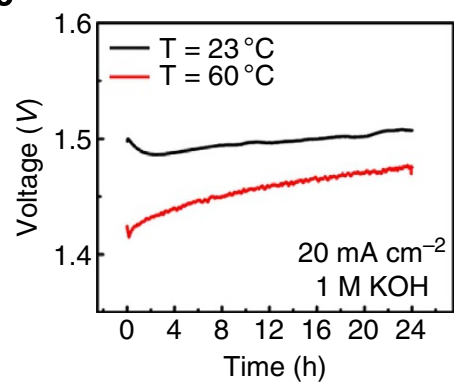

b

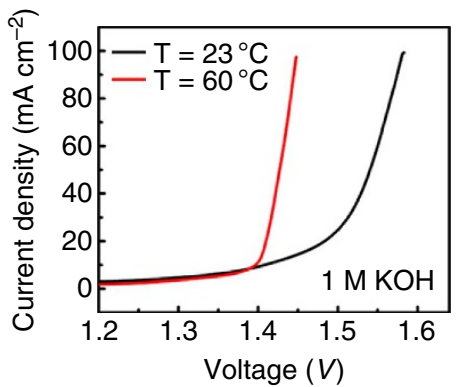

d

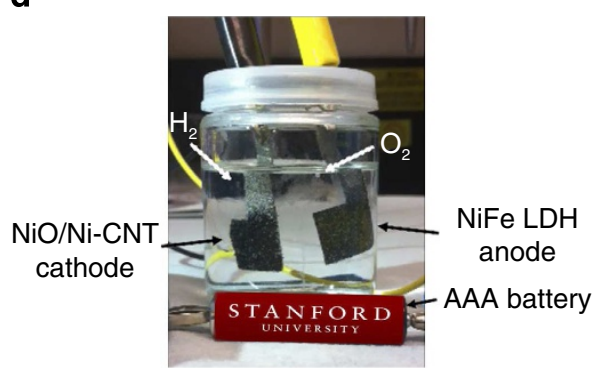

Figure 4 | High-performance NiO/Ni-CNT cathode for water splitting with a single battery. (a) Linear sweep voltametry of NiO/Ni-CNT, Pt/C deposited on $\mathrm{Ni}$ foam and pure $\mathrm{Ni}$ foam at a scan rate of $1 \mathrm{mVs}^{-1}$ under the loading of $8 \mathrm{mg} \mathrm{cm}^{-2}$ in $1 \mathrm{M} \mathrm{KOH}$. For uncompensated curve, please refer to Supplementary Fig. 10. (b) Linear sweepment voltametry of water electrolysis using NiO/Ni-CNT as HER catalyst and NiFe LDH as OER catalyst (both loaded into $\mathrm{Ni}$ foam at a loading of $8 \mathrm{mg} \mathrm{cm}^{-2}$ based on the active mass) in $1 \mathrm{M} \mathrm{KOH}$ under different temperature. (c) Chonopotentiometry of water electrolysis using NiO/Ni-CNT and NiFe LDH at a constant current density of $20 \mathrm{~mA} \mathrm{~cm}^{-2}$ in $1 \mathrm{M} \mathrm{KOH}$. (d) Demonstration of water-splitting device powered by an AAA battery with a nominal voltage of $1.5 \mathrm{~V}$.

partly due to difficulties in theoretical modelling by density functional theory of HER processes in basic solutions involving charged species participating in the reactions. Future work will address this challenge and perform in situ spectroscopic techniques to glean the reaction mechanisms and pinpoint the HER active sites in the $\mathrm{NiO} / \mathrm{Ni}$ material.

In summary, we discovered nanoscale $\mathrm{NiO} / \mathrm{Ni}$ heterostructure attached to CNT network as a novel HER catalyst. The structure of $\mathrm{Ni}$ cores partially covered with small $\mathrm{NiO}$ nanoparticles was created by a simple process of $\mathrm{Ni}(\mathrm{OH})_{2}$ decomposition involving CNT substrate delaying the $\mathrm{Ni}(\mathrm{OH})_{2}$ reduction and $\mathrm{Ni}$ aggregation. An efficient electrolyzer achieving $\sim 20 \mathrm{mAcm}^{-2}$ at a voltage of $1.5 \mathrm{~V}$ with good stability was demonstrated. The high activity of $\mathrm{NiO} / \mathrm{Ni}-\mathrm{CNT}$ was possibly attributed to the nanoscopic $\mathrm{NiO} / \mathrm{Ni}$ interfaces in the heterostructure. The highly active $\mathrm{NiO} /$ $\mathrm{Ni}$ heterostructure-based catalyst with low cost, earth abundance and environmental friendliness is promising for future watersplitting devices.

\section{Methods}

Oxidization of multi-walled carbon nanotubes. MWCNTs were oxidized by a modified Hummers method. MWCNTs ( $1 \mathrm{~g}$ ) were purified by calcinations at $500^{\circ} \mathrm{C}$ and washing with $40 \mathrm{ml}$ of diluted hydrochloric acid $(10 \mathrm{wt} \%)$ to remove metal residues and amorphous carbon. The purified MWCNTs were repeatedly washed with water and collected. After drying overnight, $\sim 23 \mathrm{ml}$ of concentrated sulphuric acid was mixed with the purified MWCNTs $(\sim 0.99 \mathrm{~g})$ in a $250-\mathrm{ml}$ round flask and stirred at room temperature for $12 \mathrm{~h}$. Subsequently, the round flask was heated to $40^{\circ} \mathrm{C}$ in an oil bath, followed by the slow addition of $\sim 100 \mathrm{mg} \mathrm{NaNO}$ and $\sim 1 \mathrm{~g} \mathrm{KMnO}_{4}$ (about the same as the mass of purified MWCNTs). After stirring at $40^{\circ} \mathrm{C}$ for $30 \mathrm{~min}, 3 \mathrm{ml}$ of water was added, followed by another $3 \mathrm{ml}$ after $5 \mathrm{~min}$. Water $(40 \mathrm{ml})$ was slowly added $5 \mathrm{~min}$ later to keep the temperature below $45^{\circ} \mathrm{C}$. After $15 \mathrm{~min}, 140 \mathrm{ml}$ of water was poured into the solution at room temperature, followed by the addition of $10 \mathrm{ml}$ of $30 \% \mathrm{H}_{2} \mathrm{O}_{2}$ to stop the reaction after 10 min. Oxidized MWCNTs were collected, washed with diluted $\mathrm{HCl}$ solution ( $5 \mathrm{wt} \%$ ) twice and then water repeatedly till $\mathrm{pH}$ is higher than or equal to 5 . The final suspension (in $\mathrm{H}_{2} \mathrm{O}$ ) was lyophilized to get solid oxidized MWCNTs.
Synthesis of NiO/Ni-CNT hybrid and control groups. In a typical synthesis of $\mathrm{NiO} / \mathrm{Ni}-\mathrm{CNT}, \sim 4 \mathrm{mg}$ oxidized MWCNTs were sonicated in $8 \mathrm{ml}$ of anhydrous $\mathrm{N}, \mathrm{N}$-dimethylformamide (DMF) for $10 \mathrm{~min}$, followed by the addition of $800 \mu \mathrm{l}$ of $0.2 \mathrm{M}$ nickel acetate $\left(\mathrm{Ni}(\mathrm{OAc})_{2}\right)$ aqueous solution. The mixture was vigorously stirred at $90{ }^{\circ} \mathrm{C}$ in an oil bath for $4 \mathrm{~h}$. Afterwards, the suspension was centrifuged and washed with $\mathrm{H}_{2} \mathrm{O}$ twice to get rid of DMF. The resuspended solution was lyophilized to get solid $\mathrm{Ni}(\mathrm{OH})_{2} /$ ox-CNT. The solid $\mathrm{Ni}(\mathrm{OH})_{2} / \mathrm{ox}-\mathrm{CNT}$ was then annealed in a tube furnace at $300^{\circ} \mathrm{C}$ and constant pressure of 1.5 torr under $\mathrm{Ar}$ atmosphere $(100 \mathrm{sccm})$ for $1 \mathrm{~h}$. The furnace was constantly pumped to get rid of the $\mathrm{H}_{2} \mathrm{O}$ and $\mathrm{O}_{2}$ generated during the reaction and maintain low pressure in the furnace. After that, the furnace was slowly cooled down to room temperature in $\sim 30 \mathrm{~min}$ and the $\mathrm{NiO} / \mathrm{Ni}$-CNT catalyst was taken out and ready for use. $\mathrm{Ni} / \mathrm{CNT}$ was synthesized by the same procedure with raised temperature to $500^{\circ} \mathrm{C}$ for the annealing process. $\mathrm{NiO} / \mathrm{CNT}$ was synthesized by the same procedure with no pumping (400 sccm Ar atmosphere, $\sim 1 \mathrm{~atm}$ pressure) for the annealing process. Pure nanoparticles were synthesized by typical procedures of $\mathrm{NiO} / \mathrm{Ni}-\mathrm{CNT}$ synthesis without CNT precursors.

Synthesis of NiFe LDH nanoparticles. In a typical procedure, $160 \mu \mathrm{l}$ of $0.5 \mathrm{M}$ $\mathrm{Ni}(\mathrm{OAc})_{2}$ aqueous solution and $32 \mu \mathrm{l}$ of $0.5 \mathrm{M} \mathrm{Fe}\left(\mathrm{NO}_{3}\right)_{3}$ were mixed with $4 \mathrm{ml}$ DMF by stirring. The mixture was heated to and maintained at $120^{\circ} \mathrm{C}$ for $16 \mathrm{~h}$ in an autoclave. The temperature was then raised to $160^{\circ} \mathrm{C}$ for $2 \mathrm{~h}$. After cooling down to room temperature, the sample was collected, centrifuged, washed with water and finally lyophilized to get solid NiFe LDH nanoparticles.

Materials characterizations. XPS samples were drop dried onto silicon substrate and measured on a PHI VersaProbe Scanning XPS Microprobe. STEM imaging and EELS mapping was performed on a Nion UltraSTEM-100, operated at $60 \mathrm{kV}$. XANES measurements were carried out at the SGM beamline of the Canadian Light Source. XANES were measured on indium foil in the surface sensitive total electron yield. Before sample measurement, data were first normalized to the incident photon flux I0 measured with a refreshed gold mesh. After measurement, data were further normalized to the edge jump between pre-edge platform and post-edge platform.

Sample preparation for electrochemical measurement. To prepare the $\mathrm{NiO} / \mathrm{Ni}-\mathrm{CNT}$ on RDE electrode, $1 \mathrm{mg} \mathrm{NiO} / \mathrm{Ni}-\mathrm{CNT}$ hybrid was mixed with $190 \mu \mathrm{l}$ water, $50 \mu \mathrm{l}$ ethanol and $10 \mu \mathrm{l} 5 \mathrm{wt} \%$ Nafion solution by at least $30 \mathrm{~min}$ sonication to form a homogeneous ink. Subsequently, $20 \mu$ l suspension was drop dried 
onto a glassy carbon electrode of $5 \mathrm{~mm}$ in diameter (loading of $0.40 \mathrm{mg} \mathrm{cm}^{-2}$ including CNTs and loading of $0.28 \mathrm{mg} \mathrm{cm}^{-2}$ for the active mass). To prepare the $\mathrm{NiO} / \mathrm{Ni}$-CNT on Ni foam electrode, $\mathrm{Ni}(\mathrm{OH})_{2} /$ ox-CNT was collected after $90^{\circ} \mathrm{C}$ oil bath process and washed with ethanol once. $\mathrm{Ni}(\mathrm{OH})_{2} / \mathrm{ox}-\mathrm{CNT}$ was then redispersed in $\sim 2 \mathrm{ml}$ ethanol. After sonication for $10 \mathrm{~min}$, all suspension was drop dried onto $1 \times 1 \mathrm{~cm} \mathrm{Ni}$ foam (1.6-mm thick, 100 p.p.i., $95 \%$ porosity, Marketech) at $90{ }^{\circ} \mathrm{C}$. The electrode was further heated at $120^{\circ} \mathrm{C}$ for $\sim 20$ min till fully dry. The as-prepared electrode was annealed in a tube furnace at $300^{\circ} \mathrm{C}$ and constant pressure of 1.5 torr under Ar atmosphere $(100 \mathrm{sccm})$ for $1 \mathrm{~h}$, same as typical procedure. The electrode with catalyst was ready for use after the annealing. The loading of $\mathrm{NiO} / \mathrm{Ni}$-CNT was determined to be $\sim 11 \mathrm{mg} \mathrm{cm}^{-2}$ by the difference of the weight of $\mathrm{Ni}$ foam before and after loading and the active mass was determined to be $\sim 8 \mathrm{mg} \mathrm{cm}^{-2}$ excluding the mass of CNT. The NiFe LDH on Ni foam electrode was produced by drop drying $8 \mathrm{mg} \mathrm{NiFe} \mathrm{LDH}$ (in $2 \mathrm{ml}$ ethanol $+3 \mathrm{wt} \%$ PTFE) onto $1 \mathrm{~cm} \times 1 \mathrm{~cm} \mathrm{Ni}$ foam.

Electrochemical measurement. HER catalytic activity measurement was performed in a standard three-electrode system controlled by a CHI 760D electrochemistry workstation. Catalyst powders cast on $\mathrm{RDE}$ or Ni foam was used as working electrode, graphite rod as counter electrode and saturated calomel electrode as reference electrode. The reference was calibrated against and converted to reversible hydrogen electrode (RHE). RDE electrode was constantly rotating at 1,600 r.p.m. to get rid of the bubbles during the measurement. Water electrolysis measurement was carried out in a standard two-electrode system by using $\mathrm{NiO} / \mathrm{Ni}$ $\mathrm{CNT}$ on Ni foam as cathode and NiFe LDH on Ni foam as anode. Linear sweep voltammetry was carried out at $1 \mathrm{mV} \mathrm{s}^{-1}$ for the polarization curves. Chronopotentiometry was measured under a constant current density of $20 \mathrm{~mA} \mathrm{~cm}^{-2}$. All polarization curves were iR corrected.

\section{References}

1. Crabtree, G. W., Dresselhaus, M. S. \& Buchanan, M. V. The hydrogen economy. Phys. Today 57, 39-44 (2004).

2. Dresselhaus, M. S. \& Thomas, I. L. Alternative energy technologies. Nature 414, 332-337 (2001).

3. Nocera, D. G. The artificial leaf. Acc. Chem. Res. 45, 767-776 (2012).

4. Walter, M. G. et al. Solar water splitting cells. Chem. Rev. 110, 6446-6473 (2010).

5. Carmo, M., Fritz, D. L., Merge, J. \& Stolten, D. A comprehensive review on PEM water electrolysis. Int. J. Hydrogen Energy 38, 4901-4934 (2013).

6. Holladay, J. D., Hu, J., King, D. L. \& Wang, Y. An overview of hydrogen production technologies. Catal. Today 139, 244-260 (2009).

7. Zeng, K. \& Zhang, D. Recent progress in alkaline water electrolysis for hydrogen production and applications. Prog. Energ. Combust. 36, 307-326 (2010).

8. Suntivich, J., May, K. J., Gasteiger, H. A., Goodenough, J. B. \& Shao-Horn, Y. A perovskite oxide optimized for oxygen evolution catalysis from molecular orbital principles. Science 334, 1383-1385 (2011).

9. Choi, C. L. et al. WS2 nanoflakes from nanotubes for electrocatalysis. Nano Res. 6, 921-928 (2013).

10. Tueysuez, H., Hwang, Y. J., Khan, S. B., Asiri, A. M. \& Yang, P. Mesoporous $\mathrm{Co} 3 \mathrm{O} 4$ as an electrocatalyst for water oxidation. Nano Res. 6, 47-54 (2013).

11. Hall, D. E. Electrodes for alkaline water electrolysis. J. Electrochem. Soc. 128, 740-746 (1981).

12. Janjua, M. B. I. \& Leroy, R. L. Electrocatalyst performance in industrial water electrolysers. Int. J. Hydrogen Energy 10, 11-19 (1985).

13. Sun, Y., Delucchi, M. \& Ogden, J. The impact of widespread deployment of fuel cell vehicles on platinum demand and price. Int. J. Hydrogen Energy 36, 11116-11127 (2011)

14. Brown, D. E., Mahmood, M. N., Turner, A. K., Hall, S. M. \& Fogarty, P. O. Low overvoltage electrocatalysts for hydrogen evolving electrodes. Int. J. Hydrogen Energy 7, 405-410 (1982).

15. Brown, D. E., Mahmood, M. N., Man, M. C. M. \& Turner, A. K. Preparation and characterization of low overvoltage transition-metal alloy electrocatalysts for hydrogen evolution in alkaline-solutions. Electrochim. Acta 29, 1551-1556 (1984).

16. Endoh, E., Otouma, H., Morimoto, T. \& Oda, Y. New raney-nickel compositecoated electrode for hydrogen evolution. Int. J. Hydrogen Energy 12, 473-479 (1987).
17. Hu, H. R. et al. Kinetics of hydrogen evolution in alkali leaching of rapidly quenched Ni-Al alloy. Appl. Catal. A-Gen. 252, 173-183 (2003).

18. Birry, L. \& Lasia, A. Studies of the hydrogen evolution reaction on Raney nickel-molybdenum electrodes. J. Appl. Electrochem. 34, 735-749 (2004).

19. Damian, A. \& Omanovic, S. Ni and Ni-Mo hydrogen evolution electrocatalysts electrodeposited in a polyaniline matrix. J. Power Sources 158, 464-476 (2006)

20. Lupi, C., Dell'Era, A. \& Pasquali, M. Nickel-cobalt electrodeposited alloys for hydrogen evolution in alkaline media. Int. J. Hydrogen Energy 34, 2101-2106 (2009).

21. McKone, J. R., Sadtler, B. F., Werlang, C. A., Lewis, N. S. \& Gray, H. B. Ni-Mo nanopowders for efficient electrochemical hydrogen evolution. Acs Catal. 3, 166-169 (2013).

22. Popczun, E. J. et al. Nanostructured nickel phosphide as an electrocatalyst for the hydrogen evolution reaction. J. Am. Chem. Soc. 135, 9267-9270 (2013).

23. Sheng, W. et al. Non-precious metal electrocatalysts with high activity for hydrogen oxidation reaction in alkaline electrolytes. Energ. Environ. Sci. 7, 1719-1724 (2014).

24. Vilekar, S. A., Fishtik, I. \& Datta, R. Kinetics of the hydrogen electrode reaction. J. Electrochem. Soc. 157, B1040-B1050 (2010).

25. Skulason, E. et al. Modeling the electrochemical hydrogen oxidation and evolution reactions on the basis of density functional theory calculations. J. Phys. Chem. C 114, 18182-18197 (2010).

26. Greeley, J., Jaramillo, T. F., Bonde, J., Chorkendorff, I. B. \& Norskov, J. K. Computational high-throughput screening of electrocatalytic materials for hydrogen evolution. Nat. Mater. 5, 909-913 (2006).

27. Sheng, W., Myint, M., Chen, J. G. \& Yan, Y. Correlating the hydrogen evolution reaction activity in alkaline electrolytes with the hydrogen binding energy on monometallic surfaces. Energ. Environ. Sci. 6, 1509-1512 (2013).

28. Gong, M. et al. An advanced Ni-Fe layered double hydroxide electrocatalyst for water oxidation. J. Am. Chem. Soc. 135, 8452-8455 (2013).

\section{Acknowledgements}

This work was supported by a Grant from Stanford GCEP, a Steinhart/Reed Award from the Stanford Precourt Institute for Energy and by the U.S. Department of Energy, Office of Basic Energy Sciences, Division of Materials Sciences and Engineering under Award \# DOE DE-SC0008684 (for carbon nanomaterials synthesis and characterization with advanced electrical properties). Work at CLS is supported by the NSERC, NRC, CIHR of Canada and the University of Saskatchewan. The electron microscopic study was supported by a Wigner Fellowship through the Laboratory Directed Research and Development Program of Oak Ridge National Laboratory, managed by UT-Battelle, LLC, for the U.S.DOE and through a user project supported by ORNL's Center for Nanophase Materials Sciences (CNMS), which is sponsored by the Scientific User Facilities Division, Office of Basic Energy Sciences, U.S. DOE. We thank Dr. Tom Regier for his technical support in collecting Ni L edge data at SGM beamline.

\section{Author contributions}

M. Gong and H.D. conceived the project and designed the experiments. M. Gong performed the synthesis and electrochemical measurement. W.Z. and S.J.P took the STEM and EELS mapping images. M.T. and B.H. performed the DFT calculation. J.Z. and Y.H. took the XANES measurement. M.Gong, W.Z., M.T., M.Guan, M.L., B.Z., Y.H., D.W., J.Y., S.J.P., B.H. and H.D. analysed the data. M.Gong, W.Z. and H.D. co-wrote the paper.

\section{Additional information}

Supplementary Information accompanies this paper at http://www.nature.com/ naturecommunications

Competing financial interests: The authors declare no competing financial interests

Reprints and permission information is available online at http://npg.nature.com/ reprintsandpermissions/

How to cite this article: Gong, M. et al. Nanoscale nickel oxide/nickel heterostructures for active hydrogen evolution electrocatalysis. Nat. Commun. 5:4695 doi: $10.1038 /$ ncomms5695 (2014). 